\title{
Pattern of the First Recurrence Has No Impact on Long-Term Survival after Curative Intent Surgery for Perihilar Cholangiocarcinomas
}

\author{
Madalina Maria Blaga, ${ }^{1}$ Vladislav Brasoveanu, ${ }^{2,3}$ Cezar Stroescu, ${ }^{1,2}$ Mihnea Ionescu, ${ }^{1,2}$ \\ Irinel Popescu, ${ }^{2,3}$ and Traian Dumitrascu $\mathbb{1}^{1,2}$ \\ 1 "Carol Davila” University of Medicine and Pharmacy, Dionisie Lupu No. 37, 030167 Bucharest, Romania \\ ${ }^{2}$ Center of General Surgery and Liver Transplant, Fundeni Clinical Institute, Fundeni No. 258, 022328 Bucharest, Romania \\ 3 "Titu Maiorescu" University, Gheorghe Petrascu No. 67A, 031593 Bucharest, Romania
}

Correspondence should be addressed to Traian Dumitrascu; traian.dumitrascu@umfcd.ro

Received 27 February 2018; Revised 30 May 2018; Accepted 13 June 2018; Published 9 August 2018

Academic Editor: Giuseppe Nigri

Copyright (C) 2018 Madalina Maria Blaga et al. This is an open access article distributed under the Creative Commons Attribution License, which permits unrestricted use, distribution, and reproduction in any medium, provided the original work is properly cited.

\begin{abstract}
Aim. To explore the pattern of the first recurrence and impact on long-term survival after curative intent surgery for perihilar cholangiocarcinomas (PHC). Materials and Methods. Patients with curative intent surgery for PHC between 1996 and 2017 were analyzed. Survival times were estimated using the Kaplan-Meier method. Comparisons were made with the log-rank test. Results. A number of 139 patients were included. The median overall survival was 26 months. A recurrence was observed in 86 patients (61.9\%), during a median follow-up time of 89 months. The median disease-free survival was 21 months with 1-, 3-, 5-, and 10 -year estimated recurrence rates of $38 \%, 60 \%, 69 \%$, and $77 \%$, respectively. A number of 57 patients (41\%) developed distant only recurrence, while 26 patients (18.7\%) presented local and distant recurrences. An isolated local recurrence was observed in 3 patients (2.2\%). The median overall survival was 15 months for patients with local recurrence, 15 months for patients with liver metastases, and 17 months for patients with peritoneal carcinomatosis $(p=0.903)$ as the first recurrence. Conclusion. Curative intent surgery for PHC is associated with high recurrence rates. Most patients will develop distant metastases, while an isolated local recurrence is uncommon. The pattern of recurrence does not appear to have a significant impact on survivals.
\end{abstract}

\section{Introduction}

Perihilar cholangiocarcinomas (PHC) are the most common variant of cholangiocarcinomas, and resection represents the single hope for a long-term survival [1].

For these patients, a curative intent surgery implies bile duct resection, locoregional lymph node dissection, caudate lobectomy, and usually a major liver resection [2]. Sometimes vascular resections are required to obtain negative resection margins [3].

This aggressive surgical approach was associated with significantly improved long-term survival rates at the expense of high morbidity rates [2], including clinically relevant complications [4]. Thus, a recent review has shown that in high-volume centers, the reported median overall survival time is $19-39$ months, while the morbidity and mortality rates are $26 \%-75 \%$ and $0 \%-14.3 \%$, respectively [2]. It appears that mortality rates are higher in Western series of patients, compared with Eastern series (13.6\% versus 2.5\%) albeit no significant differences of survivals were observed [5].

Despite improved survival rates with this aggressive approach, recurrence after curative intent surgery for PHC is a frequent event. Thus, the reported median disease-free survival times are 12-20 months [6]. Negative resection margins are of utmost importance for the disease-free survival $[6,7]$. 
So far, there are only few studies exploring the pattern of the first recurrence after curative intent surgery for PHC [7-17]. However, the impact of the recurrence pattern on the long-term outcomes remains largely unknown. The knowledge of the pattern of the first recurrence and the impact on long-term outcomes after curative intent surgery for PHC might be of benefit for a better management of these patients.

The present study is aimed at exploring the pattern of the first recurrence and the impact on long-term outcomes after curative intent surgery for PHC, in a single center experience including a relatively large number of patients.

\section{Materials and Methods}

2.1. Patients. Between 1996 and 2017 (November 1st), a number of 150 patients underwent curative intent surgery for PHC, diagnosed at final pathology examination. A curative intent surgery was considered a surgical procedure associated either with negative resection margins or microscopic positive resection margins. Our criteria of resectability for PHC were described elsewhere [6].

Data were retrospectively reviewed from a prospective electronic database established in our institution.

2.2. Outcomes. The imaging follow-up of these patients included computed tomography and/or magnetic resonance imaging every 3 months during the first 2 years after resection and every 6 months after till 5 years after resection. Outside these dates, an imaging exploration was performed when the clinical suspicion of recurrence was raised. Recurrence was diagnosed either with imaging methods during the follow-up time or at relaparotomy for late complications. A local recurrence was defined as recurrence at the liver hilum (including hilar lymph node metastases), liver resection margin, distal common bile duct, or cholangiojejunostomy site. All other situations were considered distant metastases.

From the survival and follow-up, analyses excluded patients with postoperative mortality within 90 days (9 patients-6\%) and those with no follow-up data (2 patients-1.3\%). Thus, the study cohort included 139 patients with a median age of 59 years (range, 21-77 years) and with slightly male predominance (75 patients-54\%). The surgical procedures and pathology data are presented in Tables 1 and 2. The median preoperative CA 19-9 serum level in the present cohort was $216 \mathrm{UI} / \mathrm{ml}$ (range, 1$12,000 \mathrm{UI} / \mathrm{ml}$ ). A number of 72 patients (51.8\%) underwent adjuvant chemotherapy.

2.3. Statistical Analyses. Statistical analyses were performed using the SPSS (Statistical Packages for Social Sciences) version 20.0 software (SPSS Inc., Chicago, IL). The MannWhitney $U$ test was used to compare continuous data between the groups, while Fisher's exact test (two-tailed) was used for categorical data. The disease-free survival time was considered the time from resection to the time of first recurrence, while the overall survival time was considered the time from resection to death occurrence or last followup (January 1st, 2018). For patients with recurrent disease,
TABLE 1: Operative procedures in 139 patients with curative intent surgery for perihilar cholangiocarcinomas.

\begin{tabular}{lc}
\hline Operative procedure & Number of patients $(\%)$ \\
\hline Simple bile duct resection & 24 patients $(17.3 \%)$ \\
Right hemihepatectomy & 37 patients $(26.6 \%)$ \\
Right trisectionectomy & 10 patients $(7.2 \%)$ \\
Left hemihepatectomy & 62 patients $(44.6 \%)$ \\
Left trisectionectomy & 1 patient $(0.7 \%)$ \\
Central hepatectomy & 1 patient $(0.7 \%)$ \\
Caudate lobectomy & 88 patients $(63.3 \%)$ \\
Portal vein resection & 22 patients $(15.8 \%)$ \\
Hepatic artery resection & 4 patients $(2.9 \%)$ \\
Pancreaticoduodenectomy & 1 patient $(0.7 \%)$ \\
\hline
\end{tabular}

TABLE 2: Pathology data in 139 patients with curative intent surgery for perihilar cholangiocarcinomas.

\begin{tabular}{lc}
\hline Parameter & \\
\hline Tumor diameter $^{\dagger}, \mathrm{cm}$ & $2.5(0.4-10)$ \\
Histology, adenocarcinoma & 136 patients $(97.8 \%)$ \\
Grade of differentiation & \\
G1 & 82 patients $(59 \%)$ \\
G2 & 42 patients $(30.2 \%)$ \\
G3 & 15 patients $(10.8 \%)$ \\
Tumor pattern type & \\
Infiltrative & 72 patients $(51.8 \%)$ \\
Nodular & 60 patients $(43.2 \%)$ \\
Papillary & 7 patients $(5 \%)$ \\
pT stage & \\
T1 & 21 patients $(15.1 \%)$ \\
T2 & 40 patients $(28.8 \%)$ \\
T3 & 56 patients $(40.3 \%)$ \\
T4 & 22 patients $(15.8 \%)$ \\
Lymph node metastases (pN1) & 54 patients $(38.8 \%)$ \\
Distant metastases* $(\mathrm{pM} 1)$ & 9 patients $(6.5 \%)$ \\
Perineural invasion & 49 patients $(35.2 \%)$ \\
Negative resection margins & 105 patients $(75.5 \%)$ \\
\hline
\end{tabular}

${ }^{\dagger}$ Median value. ${ }^{*}$ Liver metastases (8 patients) and celiac trunk lymph node metastasis (1 patient).

time to recurrence was considered the time from resection to first recurrence. The median follow-up time was calculated using the reversed Kaplan-Meier method. The survival times were calculated using the Kaplan-Meier method and comparisons between the groups were made with the logrank test. $p$ values less than 0.05 were considered statistically significant.

\section{Results}

The median overall survival time for the entire cohort was 26 months (range, 2-205 months) with estimated 1-, 3-, 
5-, and 10 -year survival rates of $75 \%, 45 \%, 29 \%$, and $15 \%$, respectively.

The median disease-free survival time for the entire cohort was 21 months (range, 2-205 months) with 1-, 3-, $5-$, and 10-year estimated probability of recurrence rates of $38 \%, 60 \%, 69 \%$, and $77 \%$, respectively, as shown in Figure 1.

During follow-up time (median: 89 months, range: 2-205 months), a number of 100 patients $(71.9 \%)$ died. In the group of death patients, the cause of death was related to tumor recurrence in 83 patients $(83 \%)$, while 17 patients (17\%) died of other causes, not related to tumor recurrence. Out of the 39 patients $(29.1 \%)$ alive at follow-up point, 3 patients (2.1\%) presented recurrence. Thus, a total number of 86 patients (61.9\%) developed recurrence during the follow-up time in the present series.

Only one patient $(0.7 \%)$ with local recurrence at distal common bile duct was amenable for reresection (i.e., pancreaticoduodenectomy), and his outcome was described elsewhere [18].

A number of 57 patients (41\%) developed distant only recurrence, while 26 patients (18.7\%) presented local and distant recurrences. An isolated local recurrence was observed in only 3 patients (2.2\%), while a liver only recurrence and a peritoneal only recurrence were observed in 21 patients (15.1\%) and 14 patients (10.1\%), respectively. Overall, 29 patients (20.9\%) presented local recurrence, 55 patients (39.6\%) liver metastases, 40 patients $(28.8 \%)$ peritoneal metastases, 6 patients $(4.3 \%)$ retroperitoneal lymph node metastases, one patient $(0.7 \%)$ lung metastases, and one patient $(0.7 \%)$ ovarian metastases at the first recurrence.

In the group of patients with recurrent disease, the median time to recurrence was 11 months (range, 2-119 months), while the median survival time from recurrence to death was 4 months (range, 1-38 months). No significant differences of time to recurrence and time from recurrence to death were observed between patients with the first local recurrence, liver metastases, and peritoneal carcinomatosis ( $p$ value $=0.091, \mathrm{~ns}$, data not shown $)$.

The median overall survival time was significantly shorter in the group of patients with recurrent disease, compared with patients with no recurrence (17 months, range: 3-129 months versus 118 months, range: $2-205$ months, $p<0.001$ ), as shown in Figure 2. However, no statistically significant differences of survivals were observed between the groups of patients with a different pattern of recurrence $(p=0.903$, ns), as shown in Figure 3. Thus, the median overall survival time was 15 months (range, 3-105 months) in the group of patients with local recurrence, 15 months (range, 3-129 months) in the group of patients with liver metastases, and 17 months (range, 3-129 months) for patients with peritoneal carcinomatosis at the first recurrence. Furthermore, no significant differences of survivals were observed between the groups of patients with liver only recurrence and peritoneal only recurrence $(p=0.472, \mathrm{~ns})$, as shown in Figure 4 .

It is worth mentioning that no significant differences were observed between the groups with isolated local recurrence, liver only recurrence, and peritoneal only recurrence with respect with the neutrophil-to-lymphocyte ratio $(p=$ $0.691, \mathrm{~ns})$, resection margin status $(p=1, \mathrm{~ns})$, caudate lobe

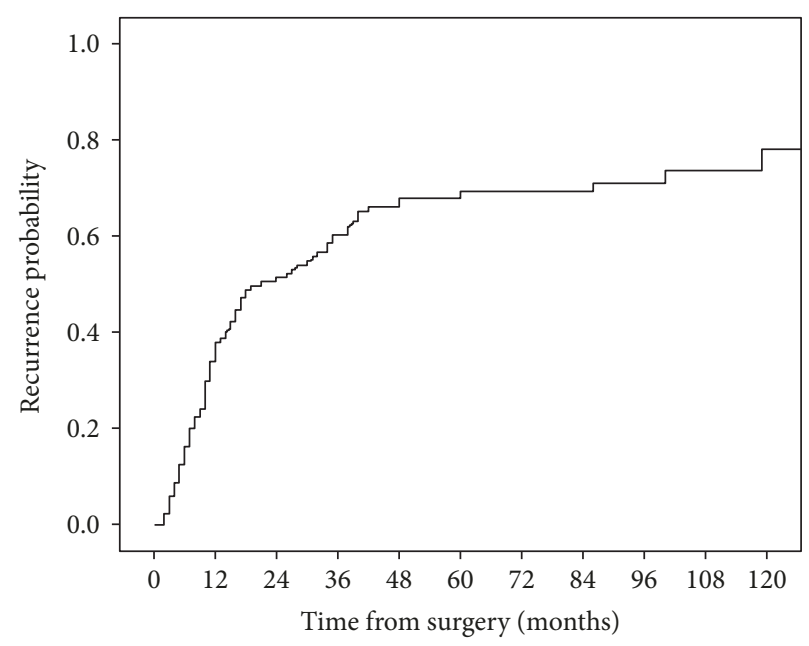

FIGURE 1: Estimated probability of recurrence after curative intent surgery for perihilar cholangiocarcinomas in 139 patients.

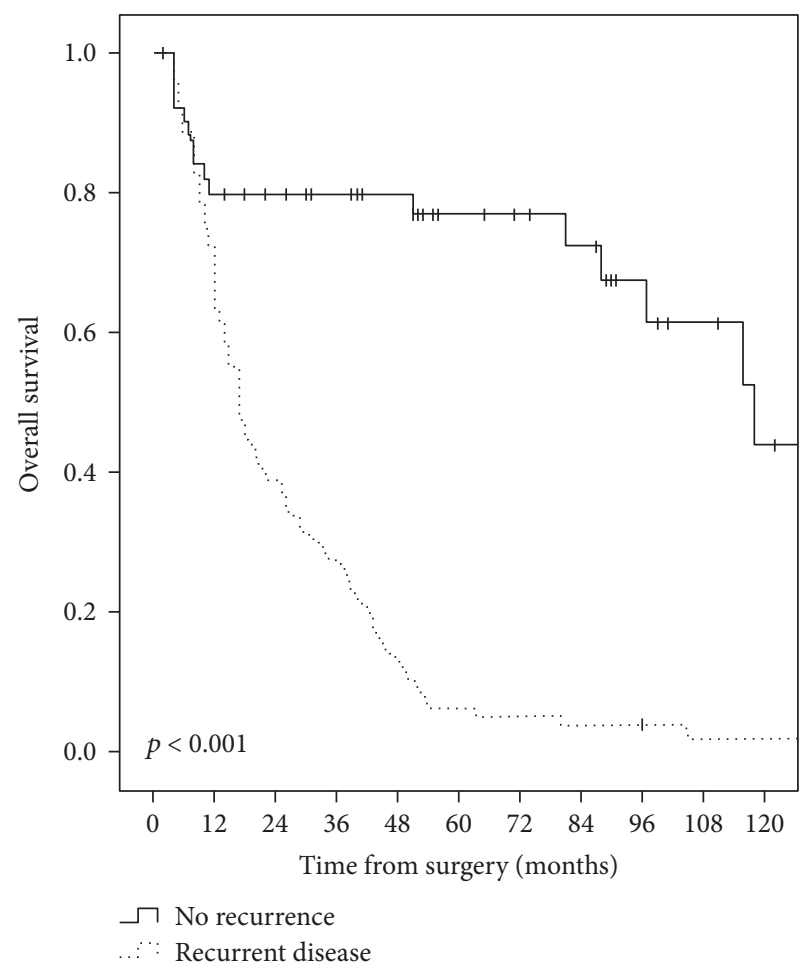

FIgURE 2: Comparative overall survival curves in patients with curative intent surgery for perihilar cholangiocarcinomas, with and without recurrent disease.

invasion ( $p=0.564$, ns), and adjuvant chemotherapy ( $p=$ 0.295 , ns). The abovementioned factors were previously identified as independent predictors for disease-free survival after curative intent surgery for perihilar cholangiocarcinomas in our cohort of patients [6]. Furthermore, no differences between the groups were observed for age, gender, CA 19-9 serum level, tumor histology, pattern type, grade of differentiation and diameter, perineural invasion, and pTNM stages ( $p$ value $=0.076$, ns, data not shown). 


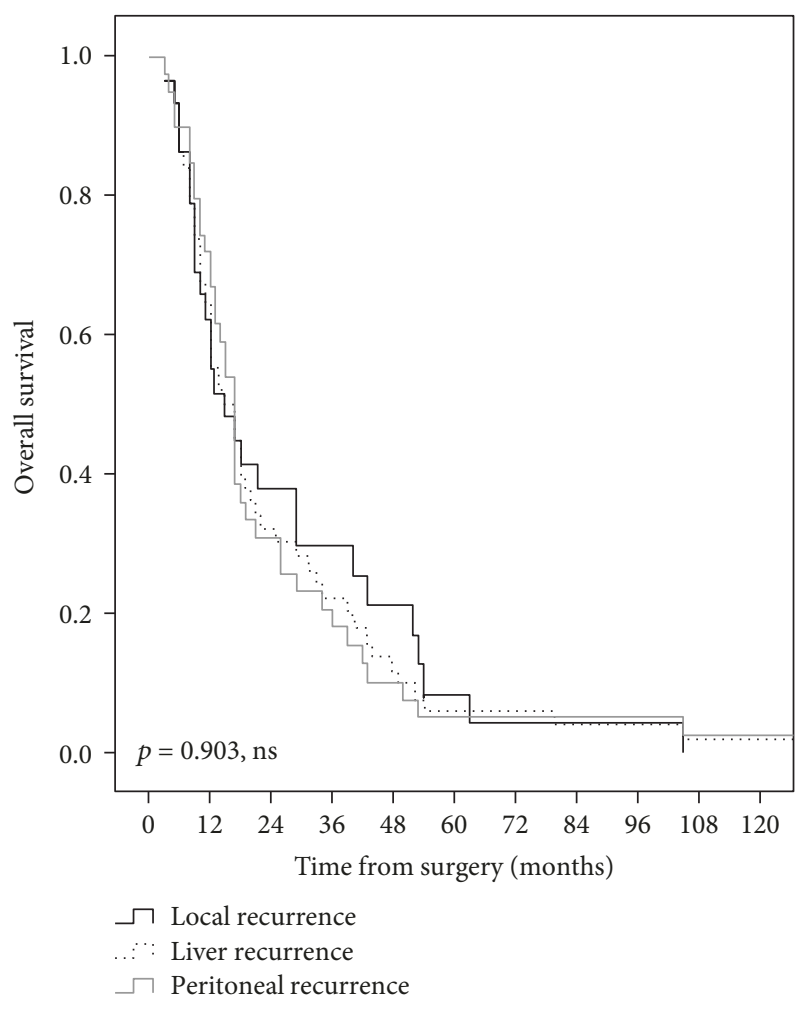

Figure 3: Comparative overall survival curves in patients with a different pattern of recurrence after curative intent surgery for perihilar cholangiocarcinomas.

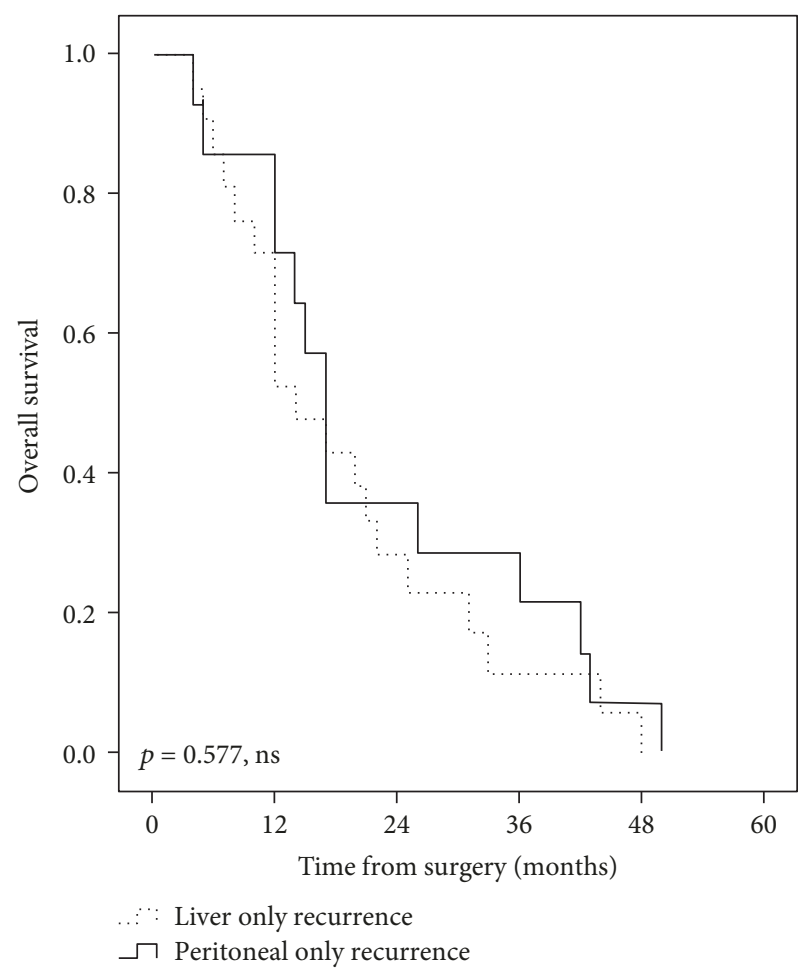

FIGURE 4: Comparative overall survival curves in patients with liver only recurrence and peritoneal only pattern of recurrence after curative intent surgery for perihilar cholangiocarcinomas.

\section{Discussion}

The knowledge of the pattern of recurrence after curative intent surgery for PHC can be used for clinical decisionmaking $[7,9,11,12,19]$. Thus, for patients who are at high risk to develop distant recurrence, it was suggested that they are more likely to benefit from adjuvant chemotherapy $[9,12]$. Recent studies have shown that adjuvant chemotherapy is an independent predictor for disease-free survival after curative intent surgery for PHC $[6,20]$. For patients who are more likely to develop local recurrence, extensive surgery to obtain negative resection margins might be warranted $[7,9,10]$. Nevertheless, the follow-up after resection might be tailored to the recurrence pattern $[9,19]$.

Previous studies (Table 3 ) have shown an overall recurrence rate of $44 \%-68 \%$ after curative intent surgery for PHC [7-11, 13-15, 17, 21], during a median follow-up time of 18-102 months [7-11, 13-15, 17, 22], with 5-year recurrence rates of $67 \%-88 \%[7,9,15,17]$. In the present series, the overall recurrence rate was $61.9 \%$ during a median follow-up time of 89 months, with a 5 -year recurrence rate of $69 \%$.

Studies from literature have observed a local recurrence in $10.1 \%-26 \%$ of patients after curative intent surgery for PHC $[7,9,14,16]$, while distant metastases at the first recurrence were observed in $36 \%-45.8 \%$ of patients $[7-11,13,14]$. The most common site for distant recurrence was the liver in most studies $[8-10,14,16]$, while peritoneum has been highlighted in few other studies [7]. An isolated local recurrence was observed only in $18 \%-19.1 \%$ of patients [7, 9]. In the present series, a local recurrence was observed in $20.9 \%$ of patients and distant metastases at the first recurrence in $59.7 \%$, with liver as the most common site. Interestingly, in the present series, an isolated local recurrence was observed in only few patients $(2.2 \%)$.

Recurrence as cause of death was observed in $91 \%$ of patients with curative intent surgery for PHC in the recent study [9] and has a detrimental effect on overall survival [13], as it was the case in the present series.

Several studies have shown a median time to the first recurrence of 12-31 months after curative intent surgery for PHC $[9,11,14,15,21]$, while the median survival time from recurrence to death was $8-8.5$ months $[7,9]$, with no significant differences between patients with local or distant recurrence $[7,9,11,14]$. Similar findings were observed in the present series where the median time to the first recurrence was 11 months, with a median survival time from recurrence to death of only 4 months and no significant differences related to the pattern of recurrence.

It is worth mentioning that the recent study has shown that patients who developed an isolated local recurrence have had significantly better overall survivals, compared with patients who developed distant metastases with or without local recurrence (33.6 months versus 22.1-22.3 months, $p=0007$ ) [17]. In the present cohort, no statistically significant differences of survivals were observed between the groups of patients with a different pattern of recurrence $(p=0.903, \mathrm{~ns})$, as shown in Figure 3 .

To date, there is no standard approach guidelines for recurrence after curative intent surgery for PHC [19]. For 
TABLE 3: Studies from the literature assessing the recurrence pattern after curative intent surgery for perihilar cholangiocarcinomas.

\begin{tabular}{|c|c|c|c|c|c|c|c|c|c|}
\hline Author, year & $\begin{array}{l}\text { Number of } \\
\text { patients } \\
\text { resected } \\
\text { for PHC }\end{array}$ & $\begin{array}{l}\text { Median } \\
\text { follow-up } \\
\text { time } \\
\text { (months) }\end{array}$ & $\begin{array}{l}\text { Median } \\
\text { disease-free } \\
\text { survival } \\
\text { (months) }\end{array}$ & $\begin{array}{l}\text { Overall } \\
\text { recurrence } \\
\text { observed } \\
\text { during } \\
\text { follow-up } \\
\text { time }(\%)\end{array}$ & $\begin{array}{c}\text { Recurrence } \\
\text { rate at } \\
5 \text { years }\end{array}$ & $\begin{array}{l}\text { Isolated } \\
\text { local } \\
\text { recurrence } \\
\text { rate }(\%)\end{array}$ & $\begin{array}{c}\text { Distant } \\
\text { metastases } \\
\text { at the first } \\
\text { recurrence } \\
\quad(\%)\end{array}$ & $\begin{array}{c}\text { Death } \\
\text { observed } \\
\text { during } \\
\text { follow-up } \\
\text { time (\%) }\end{array}$ & $\begin{array}{l}\text { Recurrence as } \\
\text { cause of death } \\
\text { (\% of total } \\
\text { deaths) }\end{array}$ \\
\hline $\begin{array}{l}\text { Jarnagin et al. } \\
{[11], 2003}\end{array}$ & 76 & 24 months & NA & $68 \%$ & NA & NA & $36 \%$ & NA & NA \\
\hline $\begin{array}{l}\text { Ito et al. } \\
{[10], 2008}\end{array}$ & 38 & 29 months & 31 months & $65.8 \%$ & NA & NA & $42.1 \%$ & NA & NA \\
\hline $\begin{array}{l}\text { Chen et al. } \\
{[8], 2009}\end{array}$ & 138 & 33 months & NA & $49.3 \%$ & NA & NA & $45.7 \%$ & NA & NA \\
\hline $\begin{array}{l}\text { Kobayashi et al. } \\
{[14], 2010}\end{array}$ & 79 & 30 months & NA & $53 \%$ & NA & NA & $43 \%$ & NA & NA \\
\hline $\begin{array}{l}\text { Saxena et al. } \\
{[15], 2011}\end{array}$ & 42 & 20 months & 15 months & $64 \%$ & $88 \%$ & NA & NA & $60 \%$ & NA \\
\hline $\begin{array}{l}\text { Wahab et al. } \\
{[22], 2012}\end{array}$ & 159 & 27 months & NA & $59.1 \%$ & NA & NA & NA & NA & NA \\
\hline $\begin{array}{l}\text { Nuzzo et al. } \\
\text { [21], 2012, } \\
\text { multicentric }\end{array}$ & 440 & NA & NA & $54.5 \%$ & NA & NA & NA & NA & NA \\
\hline $\begin{array}{l}\text { Groot et al. } \\
{[9], 2015,} \\
\text { multicentric }\end{array}$ & 306 & 48 months & 26 months & $58 \%$ & $67 \%$ & $18 \%$ & $40 \%$ & $70 \%$ & $91 \%$ \\
\hline $\begin{array}{l}\text { Kang et al. } \\
{[13], 2016}\end{array}$ & 260 & 102 months & NA & $55 \%$ & NA & NA & $39.7 \%$ & NA & NA \\
\hline $\begin{array}{l}\text { Komaya et al. } \\
{[7], 2018}\end{array}$ & 402 & 43 months & NA & $61.7 \%$ & $71.4 \%$ & $19.1 \%$ & $45.8 \%$ & $64.9 \%$ & NA \\
\hline $\begin{array}{l}\text { Zhang et al. } \\
\text { [17], 2018, } \\
\text { multicentric }\end{array}$ & 225 & 18 months & NA & $44 \%$ & $70.5 \%$ & NA & NA & NA & NA \\
\hline $\begin{array}{l}\text { Present series, } \\
2018\end{array}$ & 139 & 89 months & 21 months & $61.9 \%$ & $68 \%$ & $2.2 \%$ & $59.7 \%$ & $71.9 \%$ & $83 \%$ \\
\hline
\end{tabular}

patients with isolated local recurrence, there is the potential benefit of reresection $[7,18]$ or radiation therapy [23], while for patients with distant metastases as the first recurrence, surgery has a limited place [8], except for some highly selected patients [24]. It appears that preoperative biliary drainage [25], associated vascular resections [3, 6, 26], and adjuvant chemotherapy [20] do not influence local or distant recurrence rates after curative intent surgery for PHC.

The recent study has shown that surgery for recurrent biliary tract cancer may prolong survival, but few patients are suitable for reresection [27]. In the present cohort, only one patient $(0.7 \%)$ with local recurrence at the distal common bile duct was amenable for reresection. Nevertheless, there are studies that reported nil reresection rates for recurrences after curative intent surgery for PHC [8].

The present study has some limitations. First, it has a retrospective design. Furthermore, the imaging surveillance was heterogeneous (some patients have had computed tomography, and some other patients have had magnetic resonance imaging; the imaging exploration was performed in a large number of imaging centers with different expertise).

\section{Conclusions}

Recurrence after curative intent surgery for PHC is a common event. Furthermore, recurrence of disease is the most frequent cause of death in these patients. Most patients will develop distant metastases, while an isolated local recurrence is uncommon. Reresection has a limited role in treatment of patients with recurrence after resection for PHC. The pattern of recurrence does not appear to have a significant impact on overall survivals.

\section{Data Availability}

Data are available at our institution in an electronic database.

\section{Conflicts of Interest}

The authors declare that there is no conflict of interest regarding the publication of this article. 


\section{References}

[1] H. L. Lewis, A. A. Rahnemai-Azar, M. Dillhoff, C. R. Schmidt, and T. M. Pawlik, "Current management of perihilar cholangiocarcinoma and future perspectives," Chirurgia, vol. 112, no. 3, pp. 193-207, 2017.

[2] I. Popescu and T. Dumitrascu, "Curative-intent surgery for hilar cholangiocarcinoma: prognostic factors for clinical decision making," Langenbeck's Archives of Surgery, vol. 399, no. 6, pp. 693-705, 2014.

[3] T. Dumitrascu, C. Stroescu, V. Brasoveanu, V. Herlea, M. Ionescu, and I. Popescu, "Curative-intent surgery for perihilar cholangiocarcinoma with and without portal vein resection - a comparative analysis of early and late outcomes," Chirurgia, vol. 112, no. 3, pp. 308-319, 2017.

[4] T. Dumitrascu, V. Brasoveanu, C. Stroescu, M. Ionescu, and I. Popescu, "Major hepatectomies for perihilar cholangiocarcinoma: predictors for clinically relevant postoperative complications using the International Study Group of Liver Surgery definitions," Asian Journal of Surgery, vol. 39, no. 2, pp. 8189,2016

[5] N. Kimura, A. L. Young, Y. Toyoki et al., "Radical operation for hilar cholangiocarcinoma in comparable Eastern and Western centers: outcome analysis and prognostic factors," Surgery, vol. 162, no. 3, pp. 500-514, 2017.

[6] T. Dumitrascu, D. Chirita, M. Ionescu, and I. Popescu, "Resection for hilar cholangiocarcinoma: analysis of prognostic factors and the impact of systemic inflammation on long-term outcome," Journal of Gastrointestinal Surgery, vol. 17, no. 5, pp. 913-924, 2013.

[7] K. Komaya, T. Ebata, Y. Yokoyama et al., "Recurrence after curative-intent resection of perihilar cholangiocarcinoma: analysis of a large cohort with a close postoperative followup approach," Surgery, vol. 163, no. 4, pp. 732-738, 2018.

[8] X. P. Chen, W. Y. Lau, Z. Y. Huang et al., "Extent of liver resection for hilar cholangiocarcinoma," The British Journal of Surgery, vol. 96, no. 10, pp. 1167-1175, 2009.

[9] K. B. Groot, J. K. Wiggers, P. J. Allen et al., "Recurrence rate and pattern of perihilar cholangiocarcinoma after curative intent resection," Journal of the American College of Surgeons, vol. 221, no. 6, pp. 1041-1049, 2015.

[10] F. Ito, R. Agni, R. J. Rettammel et al., "Resection of hilar cholangiocarcinoma: concomitant liver resection decreases hepatic recurrence," Annals of Surgery, vol. 248, no. 2, pp. 273-279, 2008.

[11] W. R. Jarnagin, L. Ruo, S. A. Little et al., "Patterns of initial disease recurrence after resection of gallbladder carcinoma and hilar cholangiocarcinoma: implications for adjuvant therapeutic strategies," Cancer, vol. 98, no. 8, pp. 1689-1700, 2003.

[12] S. J. Jung, S. M. Woo, H. K. Park et al., "Patterns of initial disease recurrence after resection of biliary tract cancer," Oncology, vol. 83, no. 2, pp. 83-90, 2012.

[13] M. J. Kang, J. Y. Jang, J. Chang et al., “Actual long-term survival outcome of 403 consecutive patients with hilar cholangiocarcinoma," World Journal of Surgery, vol. 40, no. 10, pp. 2451-2459, 2016.

[14] A. Kobayashi, S. Miwa, T. Nakata, and S. Miyagawa, "Disease recurrence patterns after R0 resection of hilar cholangiocarcinoma," British Journal of Surgery, vol. 97, no. 1, pp. 56-64, 2010.

[15] A. Saxena, T. C. Chua, F. C. Chu, and D. L. Morris, "Improved outcomes after aggressive surgical resection of hilar cholangiocarcinoma: a critical analysis of recurrence and survival,"
American Journal of Surgery, vol. 202, no. 3, pp. 310-320, 2011.

[16] S. C. Song, D. W. Choi, A. W. Kow et al., "Surgical outcomes of 230 resected hilar cholangiocarcinoma in a single centre," ANZ Journal of Surgery, vol. 83, no. 4, pp. 268-274, 2013.

[17] X. F. Zhang, E. W. Beal, J. Chakedis et al., "Defining early recurrence of hilar cholangiocarcinoma after curative-intent surgery: a multi-institutional study from the US extrahepatic biliary malignancy consortium," World Journal of Surgery, pp. 1-11, 2018.

[18] D. Chirita, M. Calita, M. Grasu et al., "Metachronous ampulla of Vater carcinoma after curative-intent surgery for Klatskin tumor," Chirurgia, vol. 110, no. 4, pp. 379-383, 2015.

[19] B. H. Kim, K. Kim, E. K. Chie et al., "Risk stratification and prognostic nomogram for post-recurrence overall survival in patients with recurrent extrahepatic cholangiocarcinoma," $H P B$, vol. 19, no. 5, pp. 421-428, 2017.

[20] B. A. Krasnick, L. X. Jin, J. T. Davidson et al., "Adjuvant therapy is associated with improved survival after curative resection for hilar cholangiocarcinoma: a multi-institution analysis from the U.S. extrahepatic biliary malignancy consortium," Journal of Surgical Oncology, vol. 117, no. 3, pp. 363-371, 2017.

[21] G. Nuzzo, F. Giuliante, F. Ardito et al., "Improvement in perioperative and long-term outcome after surgical treatment of hilar cholangiocarcinoma: results of an Italian multicenter analysis of 440 patients," Archives of Surgery, vol. 147, no. 1, pp. 26-34, 2012.

[22] M. A. Wahab, A. M. Sultan, T. Salah et al., "Caudate lobe resection with major hepatectomy for central cholangiocarcinoma: is it of value?," Hepato-Gastroenterology, vol. 59, no. 114, pp. 321-324, 2012.

[23] Z. Ghiassi-Nejad, P. Tarchi, E. Moshier et al., "Prognostic factors and patterns of locoregional failure after surgical resection in patients with cholangiocarcinoma without adjuvant radiation therapy: optimal field design for adjuvant radiation therapy," International Journal of Radiation Oncology, Biology, Physics, vol. 99, no. 4, pp. 805-811, 2017.

[24] M. Yamada, T. Ebata, Y. Yokoyama et al., "Pulmonary metastasis after resection of cholangiocarcinoma: incidence, resectability, and survival," World Journal of Surgery, vol. 41, no. 6, pp. 1550-1557, 2017.

[25] X. F. Zhang, E. W. Beal, K. Merath et al., "Oncologic effects of preoperative biliary drainage in resectable hilar cholangiocarcinoma: percutaneous biliary drainage has no adverse effects on survival," Journal of Surgical Oncology, vol. 117, no. 6, pp. 1267-1277, 2017.

[26] G. V. Schimizzi, L. X. Jin, J. T. Davidson et al., "Outcomes after vascular resection during curative-intent resection for hilar cholangiocarcinoma: a multi-institution study from the US extrahepatic biliary malignancy consortium," $H P B$, vol. 20, no. 4, pp. 332-339, 2017.

[27] Y. Miyazaki, T. Kokudo, K. Amikura et al., "Survival of surgery for recurrent biliary tract cancer: a single-center experience and systematic review of literature," Japanese Journal of Clinical Oncology, vol. 47, no. 3, pp. 206-212, 2017. 


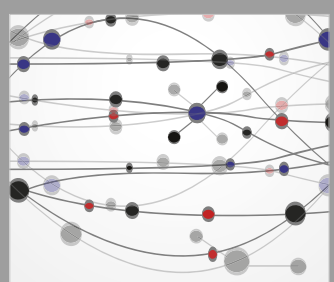

The Scientific World Journal
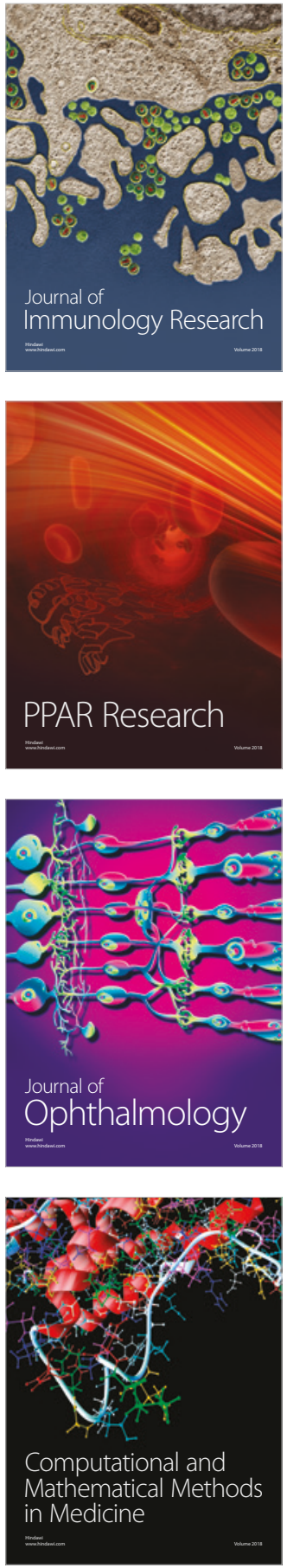

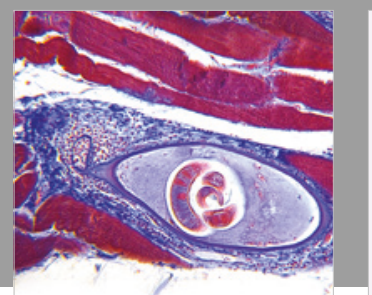

Gastroenterology Research and Practice

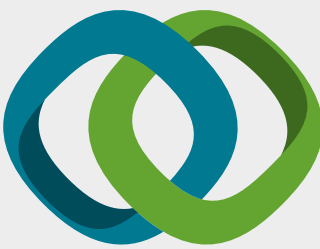

\section{Hindawi}

Submit your manuscripts at

www.hindawi.com
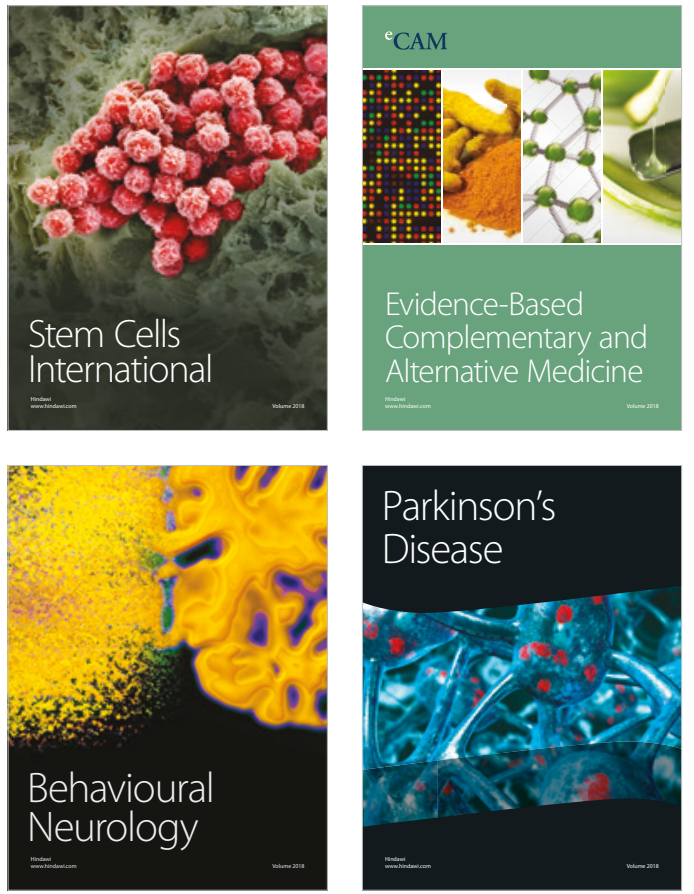

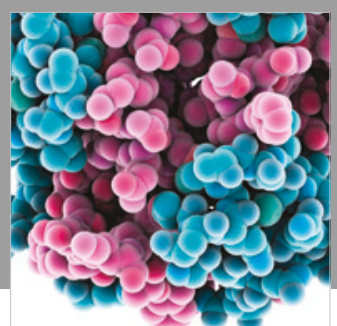

ournal of

Diabetes Research

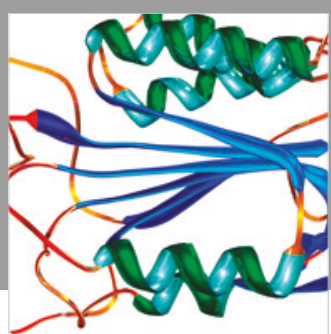

Disease Markers
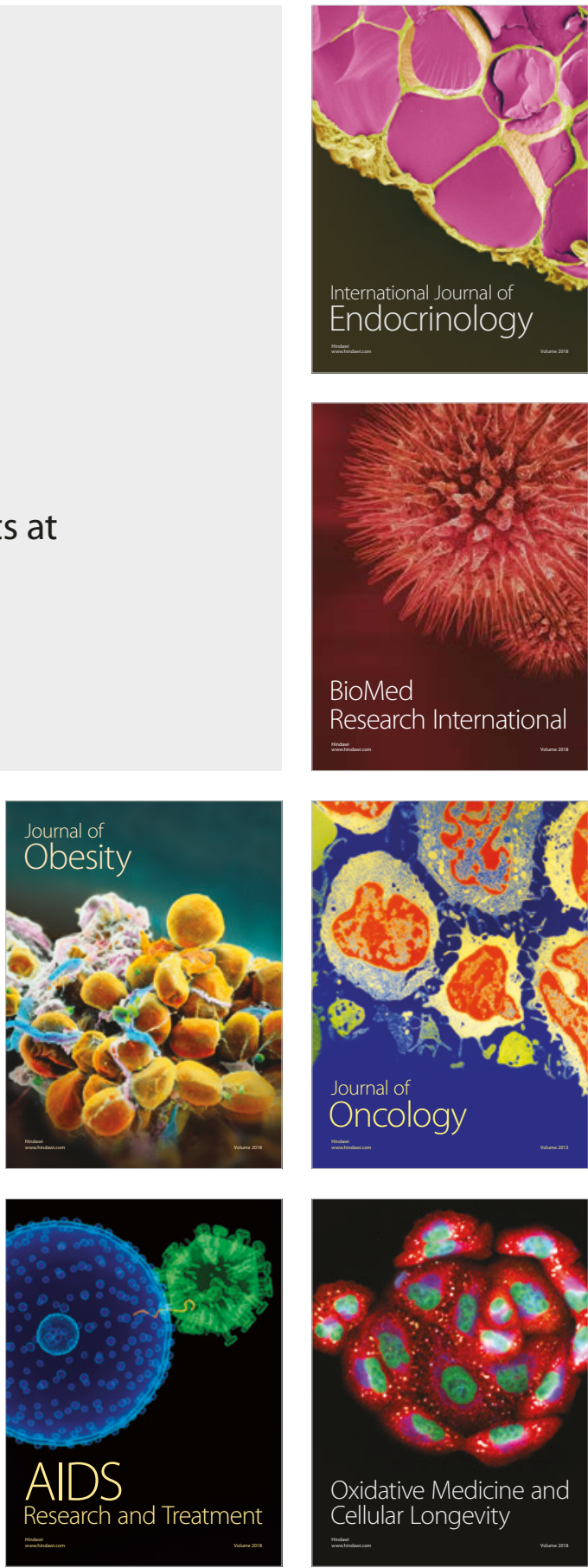